\title{
A randomized, controlled trial of initial anti-retroviral therapy with abacavir/lamivudine/zidovudine twice-daily compared to atazanavir once-daily with lamivudine/zidovudine twice-daily in HIV-infected patients over 48 weeks (ESSI 00327, the ACTION Study)
}

\author{
Princy N Kumar* ${ }^{* 1}$, Patricia Salvato ${ }^{\dagger 2}$, Anthony LaMarca ${ }^{\dagger 3}$, Edwin DeJesus ${ }^{\dagger 4}$, \\ Parul Patel ${ }^{\dagger 5}$, Daniel McClernon ${ }^{\dagger 5}$, Allison Florance ${ }^{\dagger 5}$ and Mark S Shaefer ${ }^{\dagger 5}$
}

Address: ${ }^{1}$ Georgetown University Medical Center, Washington, DC, USA, ${ }^{2}$ Diversified Medical Practice, Houston, TX, USA, ${ }^{3}$ Therafirst Medical Centers Inc, Ft. Lauderdale, FL, USA, ${ }^{4}$ Orlando Immunology Center, Orlando, FL, USA and ${ }^{5}$ Previous address: GlaxoSmithKline, Research Triangle Park, NC, USA

Email: Princy N Kumar* - kumarp@gunet.georgetown.edu; Patricia Salvato - psalv36147@aol.com; Anthony LaMarca - tony@therafirst.com; Edwin DeJesus - edejesus@oicorlando.com; Parul Patel - parul.x.patel@gsk.com; Daniel McClernon - mcclernonllc@gmail.com; Allison Florance - allison.m.florance@gsk.com; Mark S Shaefer - mark.s.shaefer@gsk.com

* Corresponding author †Equal contributors

Published: 9 April 2009

AIDS Research and Therapy 2009, 6:3 doi:10.1186/1742-6405-6-3
Received: 12 November 2008

Accepted: 9 April 2009

This article is available from: http://www.aidsrestherapy.com/content/6/1/3

(c) 2009 Kumar et al; licensee BioMed Central Ltd.

This is an Open Access article distributed under the terms of the Creative Commons Attribution License (http://creativecommons.org/licenses/by/2.0), which permits unrestricted use, distribution, and reproduction in any medium, provided the original work is properly cited.

\begin{abstract}
Background: Traditional first line regimens containing a non-nucleoside reverse transcriptase inhibitor or protease inhibitor may not be suitable for a subset of antiretroviral-naïve patients such as those with certain co-morbidities, women of child-bearing potential, and intolerability to components of standard first line therapy. This study was conducted to determine if alternate treatment options may meet the needs of both general and special patient populations. The ACTION study was a randomized, open-label, multicenter, 48-week trial that compared the safety and efficacy of a triple nucleoside regimen versus a protease inhibitor plus a dual nucleoside regimen in HIV-I treatment-naïve subjects.
\end{abstract}

Results: 279 HIV-infected subjects with HIV-I RNA (VL) $>5000$ but $<200,000$ copies $/ \mathrm{mL}(\mathrm{c} / \mathrm{mL})$ and CD4+ count $\geq 100$ cells $/ \mathrm{mm}^{3}$ were randomized (I:I) to receive abacavir sulfate/lamivudine/zidovudine (ABC/3TC/ZDV) twice-daily or atazanavir (ATV) once-daily plus lamivudine/zidovudine (3TC/ZDV) twicedaily. Protocol-defined virologic failure was based on multiple failure criteria.

Non-inferiority of $A B C / 3 T C / Z D V$ to ATV+3TC/ZDV was established with $62 \%$ vs. $59 \%$ of subjects achieving a $V L<50 \mathrm{c} / \mathrm{mL}$ at week 48 , [ITT(E), M/S $=F, 95 \% \mathrm{Cl}:-5.9$, I0.4]. Similar results were observed in the $230(82 \%)$ subjects with baseline $V L<100,000 \mathrm{c} / \mathrm{mL}$ (ABC/3TC/ZDV vs. ATV+3TC/ZDV), $66 \%$ vs. 59\%; 95\% Cl: -5.6, 19.5. However, ABC/3TC/ZDV did not meet the non-inferiority criterion compared to ATV+3TC/ZDV in the 48 subjects with baseline VL $\geq 100,000 \mathrm{c} / \mathrm{mL}, 39 \%$ vs. $60 \%$; $95 \% \mathrm{Cl}:-49.2,7.4$, respectively. Protocol-defined virologic failure was similar between groups.

Conclusion: $A B C / 3 T C / Z D V$ demonstrated comparable virologic efficacy to ATV+3TC/ZDV in this population over 48 weeks. In those with a baseline VL $\geq 100,000 \mathrm{c} / \mathrm{mL}$, subjects in the ATV+3TC/ZDV showed better virologic efficacy. Both regimens offer benefits in select therapy-naïve subjects.

Trial Registration: [Clinical Trials Identifier, NCT00082394]. 


\section{Background}

For the majority of ART-naïve, HIV-1 infected patients, the choice of an initial antiretroviral regimen continues to contain either a non-nucleoside reverse transcriptase inhibitor (NNRTI) or a boosted protease inhibitor (PI) in combination with two nucleoside reverse transcriptase inhibitors (NRTIs) [1]. However, there is an important subset of patients for which these first line regimens are unsuitable for a variety of reasons including presence of co-morbidities such as metabolic syndrome, underlying severe depression, drug-drug interactions, inability to tolerate low-dose ritonavir, and women of child-bearing potential. Additionally, as the population ages, patients are more likely to be on polypharmacy. For these groups of patients, it is important to select a regimen that is both individualized and provides suitable efficacy and safety compared to first-line regimens. The present study was conducted to determine if alternate treatment options may meet the needs of both general and special patient populations.

Triple NRTI therapy with the fixed dose combination of abacavir sulfate, lamivudine and zidovudine (ABC 300 mg, 3TC 150 mg, ZDV 300 mg; Trizivir ${ }^{\circledR}$ GlaxoSmithKline, Research Triangle Park, NC) has several advantages to other HAART regimens including convenience to facilitate adherence, low pill burden, no food or water restrictions, generally favorable safety and metabolic profile, and few drug-drug interactions. The safety and efficacy of abacavir sulfate, lamivudine, and zidovudine (ABC/3TC/ZDV) or its components have been demonstrated in several randomized trials of ART-naïve subjects [2-4].

Study CNA3014 was an open-label, randomized, multicenter trial comparing triple nucleoside therapy with abacavir sulfate (ABC 300 mg; Ziagen ${ }^{\circledR}$, GlaxoSmithKline, Research Triangle Park, NC) plus fixed dose lamivudine/ zidovudine (3TC 150 mg, ZDV 300 mg; Combivir ${ }^{\circledR}$, GlaxoSmithKline, Research Triangle Park, NC) both administered twice-daily (BID) versus indinavir (IDV) thrice-daily $+3 T C / Z D V$ BID in ART-naïve subjects. At week 48, 60\% of subjects in the $\mathrm{ABC}+3 \mathrm{TC} / \mathrm{ZDV}$ group and $50 \%$ in the IDV+3TC/ZDV group achieved a plasma HIV-1 RNA (VL) $<50 \mathrm{c} / \mathrm{mL}$. In stratified analyses, results were similar among groups regardless of screening VL ( $<$ or $\geq 100,000$ $\mathrm{c} / \mathrm{mL}$ ) in contrast to lower virologic responses observed with $\mathrm{ABC}+3 \mathrm{TC} / \mathrm{ZDV}$ in subjects with $\mathrm{VL}>100,000 \mathrm{c} / \mathrm{mL}$ in an earlier double-blind, placebo-controlled study, CNAAB3005 [2,3].

Study ESS40002 was a randomized, open-label, threearm, international, 96-week trial that evaluated 1) ABC/ 3TC/ZDV, 2) NFV+3TC/ZDV, and 3) NFV+3TC+stavudine $(\mathrm{d} 4 \mathrm{~T})$ in a racially diverse ART-naive population of which $50 \%$ were female. Through 96 weeks, $41 \%$ vs. $39 \%$ vs.
$33 \%$ of $\mathrm{ABC} / 3 \mathrm{TC} / \mathrm{ZDV}, \quad \mathrm{NFV}+3 \mathrm{TC} / \mathrm{ZDV}$, and $\mathrm{NFV}+3 \mathrm{TC}+\mathrm{d} 4 \mathrm{~T}$ treated subjects, respectively, achieved a $\mathrm{VL}<50 \mathrm{c} / \mathrm{mL}$. Subjects with a low baseline VL $(<100,000$ $\mathrm{c} / \mathrm{mL}$ ) responded comparably regardless of randomized treatment. In contrast, subjects in the $\mathrm{ABC} / 3 \mathrm{TC} / \mathrm{ZDV}$ group with a higher baseline VL $(>100,000$ but $<200,000$ $\mathrm{c} / \mathrm{mL}$ ) demonstrated greater virologic response (53\%) compared with NFV+3TC/ZDV (29\%) and NFV+3TC+d4T (42\%) at week 96 [4].

The AIDS Clinical Trial Group (ACTG) 5095 study team found that triple nucleoside therapy with $\mathrm{ABC} / 3 \mathrm{TC} / \mathrm{ZDV}$ resulted in a significantly shorter time to virologic failure regardless of baseline viral load when compared to a pooled EFV-containing regimen of $\mathrm{ABC} / 3 \mathrm{TC} / \mathrm{ZDV}$ and 3TC/ZDV [5]. At week 48, 61\% of subjects receiving ABC/ $3 \mathrm{TC} / \mathrm{ZDV}$ compared with $83 \%$ on pooled EFV-containing regimens achieved an $\mathrm{HIV}-1 \mathrm{RNA}<50 \mathrm{c} / \mathrm{mL}$, the superior virologic response of the latter attributable to EFV. Inferior virologic responses among subjects randomized to the $\mathrm{ABC} / 3 \mathrm{TC} / \mathrm{ZDV}$ arm resulted in early termination of this study arm and removal of triple nucleoside regimens as a first-line therapy option from the US Department of Health and Human Services (DHHS) guidelines in ARTnaïve subjects [6]. Surprisingly, this trend had not been observed in earlier trials with $\mathrm{ABC} / 3 \mathrm{TC} / \mathrm{ZDV}$ when compared to PI-based regimens with baseline VL up to $300,000 \mathrm{c} / \mathrm{mL}[2,3]$. Therefore, given the totality of data on the safety, tolerability, and efficacy of ABC/3TC/ZDV compared to other initial ART regimens and consistent with the DHHS Guidelines, the combination of $\mathrm{ABC} /$ 3TC/ZDV remains a reasonable option for the treatment of select ART-naïve subjects.

Atazanavir sulfate (ATV; Reyataz ${ }^{\circledR}$, Bristol-Myers Squibb, Princeton, NJ) is a protease inhibitor that may also be a useful alternative therapy option in select patient populations. Atazanavir has several attributes including oncedaily (QD) administration without ritonavir in ART-naïve subjects and a favorable lipid profile. However, scleral icterus and jaundice secondary to bilirubin elevations have been reported in subjects receiving atazanavir [7]. The safety and efficacy of atazanavir has been demonstrated in several randomized trials. Study AI424-034 was a pivotal, randomized, double blind, multicenter trial comparing atazanavir QD versus efavirenz QD each in combination with the 3TC/ZDV fixed-dose combination tablet BID. Through 48 weeks of therapy, $32 \%$ vs. $37 \%$ of subjects treated with ATV+3TC/ZDV vs. EFV+3TC/ZDV maintained viral suppression below $50 \mathrm{c} / \mathrm{mL}$ [8].

In a select population of ART-naïve HIV-1 infected subjects with low viral loads, ABC/3TC/ZDV and ATV+3TC/ ZDV may offer similar benefits versus ritonavir-boosted PI or NNRTI-containing regimens. Therefore in the ACTION 
study, [Clinical Trials Identifier, NCT00082394], we compared the safety, tolerability, and efficacy of $\mathrm{ABC} / 3 \mathrm{TC} /$ ZDV versus atazanavir plus 3TC/ZDV over 48 weeks in ART-naïve HIV-1 infected subjects with baseline VL $\geq$ 5000 and $<200,000 \mathrm{c} / \mathrm{mL}$.

\section{Methods \\ Study Design}

ESS100327 was a phase IV, randomized, non-inferiority, open-label, 48 week study comparing a fixed dose combination triple nucleoside regimen containing abacavir sulfate, lamivudine, and zidovudine (ABC/3TC/ZDV) administered twice-daily to a protease inhibitor based regimen of atazanavir (ATV) administered once daily with a fixed dose tablet of two nucleosides, lamivudine and zidovudine (3TC/ZDV), administered twice daily. Patients were recruited from 46 sites in the USA and Mexico and were eligible for enrollment if they were infected with HIV-1, aged 18 years or older, ART-naïve and had plasma HIV-1 RNA $\geq 5000$ but $<200,000 \mathrm{c} / \mathrm{mL}$ and CD4+ cell count $\geq 100$ cells $/ \mathrm{mm}^{3}$. Subjects were excluded if they had medical conditions or required medications that could compromise their safety or interfere with drug absorption, or if they had protocol-specific abnormal laboratory values.

This study was approved by ethics committees at each participating site and all subjects provided written informed consent. The study was conducted in accordance with Good Clinical Practice.

Treatment allocation was based on a central randomization schedule stratified by screening HIV-1 RNA $(<$ or $\geq$ $100,000 \mathrm{c} / \mathrm{mL}$ ). Patients were randomized 1:1 to receive either ABC/3TC/ZDV as one tablet twice daily (BID) or 2$200 \mathrm{mg}$ capsules of ATV once daily (QD) plus one tablet of 3TC/ZDV administered BID. Subjects randomized to $\mathrm{ABC} / 3 \mathrm{TC} / \mathrm{ZDV}$ and diagnosed with a suspected abacavir hypersensitivity reaction (ABC HSR) were permitted a switch to 3TC/ZDV BID + tenofovir disoproxil fumarate (TDF) $300 \mathrm{mg}$ QD. Subjects randomized to ATV+3TC/ ZDV who experienced ATV treatment-limiting toxicity (specifically jaundice or scleral icterus secondary to bilirubin elevations) were permitted a switch to fosamprenavir calcium (FPV) 1400 mg BID + 3TC/ZDV BID.

\section{Assessments and Outcomes}

Patients were evaluated at screening, Day 1 (baseline), and at weeks 2, 4, 8, 12, 16, 20, 24, 32, 40, and 48 and withdrawal. Clinical and laboratory assessments including HIV-1 viral load, CD4+/CD8+ lymphocyte subsets, clinical chemistry, hematology, serum lipid panels, insulin, and hemoglobin $\mathrm{A} 1 \mathrm{C}$ were performed regularly throughout the study. Insulin resistance and sensitivity were assessed on fasting subjects periodically using the homeostasis model assessment of insulin resistance (HOMA-IR) and the quantitative insulin-sensitivity check index (QUICKI), respectively. US Centers for Disease Control and Prevention (CDC) classification was assessed and samples for hepatitis B and C serology and pregnancy tests were performed at baseline and at investigator discretion, where appropriate. Plasma for genotypic drug resistance testing was collected at baseline and at any confirmatory visits for virologic failure.

HIV-1 RNA was measured by the Roche COBAS Amplicor HIV-1 Monitor test, Version 1.5 and the Roche COBAS Amplicor HIV-1 Ultrasensitive Monitor test, Version 1.5 (Branchburg, NJ, USA). Genotypic analyses were performed by GlaxoSmithKline Clinical Virology (Research Triangle Park, NC) using the TruGene HIV-1 Genotyping assay and by Monogram Biosciences (South San Francisco, CA, USA) using the Phenosense HIV assay, respectively. All other laboratory testing was performed centrally by Quest Laboratories (Van Nuys, CA, USA).

The primary efficacy endpoint was the proportion of subjects with HIV-1 RNA $<50 \mathrm{c} / \mathrm{mL}$ at week 48 who did not meet the definition of virologic failure through week 48 using an intent-to-treat exposed analysis [ITT(E)]. Due to the concerns raised by the ACTG 5095 study, multiple, stringent criteria for protocol-defined virologic failure was established as shown in Table 1. The primary safety endpoints were the frequency of treatment-limiting adverse events, Grade 2-4 adverse events, and serious adverse events over 24 and 48 weeks.

Secondary endpoints included the proportion of subjects with HIV-1 RNA $<50 \mathrm{c} / \mathrm{mL}$ at weeks 24 and 48 in those not meeting protocol-defined virologic failure. Subjects with regimen switches for suspected ABC HSR or ATV treatment-limiting toxicity were analyzed as treatment failures (switch = failure, $\mathrm{S}=\mathrm{F}$ ) and in sensitivity analyses in which the switch was not treated as a failure. Additional secondary endpoints included proportion of subjects with HIV-1 RNA $<400 \mathrm{c} / \mathrm{mL}$ at weeks 24 and 48, change in plasma HIV-1 RNA and CD4+ cell count from baseline, time to loss of virologic response (TLOVR), change in fasting lipids, insulin, and glucose, adherence, and development of genotypic and phenotypic resistance at virologic failure.

\section{Statistical Analysis}

Efficacy and safety analyses included all subjects that were treated before withdrawal (intent-to-treat exposed [ITT(E)]). Assuming a success rate of 0.58 for the $\mathrm{ABC} /$ 3TC/ZDV BID group and 0.50 for the ATV QD + 3TC/ZDV BID group, a total of 280 (140 subjects per treatment arm) provided greater than $90 \%$ power (one-sided, $\alpha=0.025$ ) to establish non-inferiority of $\mathrm{ABC} / 3 \mathrm{TC} / \mathrm{ZDV}$ compared 
Table I: Virologic Failure Definition

Prior to or at Week 24

I. Failure to have $\geq$ I log HIV-I RNA drop from baseline by week 12

2. Reduction of plasma HIV-I RNA to $<50$ copies $/ \mathrm{mL}$ on two occasions followed by increase of $\geq 400$ copies $/ \mathrm{mL}$ on two consecutive times prior to week 24*

3. Failure to have $<400$ copies $/ \mathrm{mL}$ by week 24

\section{After Week 24}

4. Plasma HIV-I RNA $\geq 400$ copies $/ \mathrm{mL}$ on two consecutive occasions after week $24 *$

5. Subject had an HIV-I RNA $\geq 400$ copies $/ \mathrm{mL}$ at week 48 with confirmation

* virologic rebound any time at or after confirmed virologic failure of $\geq 1265$ copies $/ \mathrm{mL}$ on two consecutive occasions resulted in subject's discontinuation from the study as a virologic withdrawal.

to ATV+3TC/ZDV using a $12 \%$ non-inferiority margin. Non-inferiority was established if the lower limit of the two-sided $95 \%$ confidence interval for the difference in proportions (ABC/3TC/ZDV BID - ATV QD + 3TC/ZDV BID) exceeded $-12 \%$.

The primary analysis was ITT(E) where missing or regimen switches for ABC HSR or ATV treatment-limiting toxicity were treated as failures $(\mathrm{M} / \mathrm{S}=\mathrm{F})$. Additional analyses included ITT(E), $M=F$ where the regimen switches were not treated as failures. Observed analyses in which missing data was not imputed were also performed with and without the regimen switches treated as failures. For the primary efficacy analysis and the corresponding sensitivity analyses, the treatment response rates in each group were stratified by the baseline HIV-1 RNA ( $<$ or $\geq 100,000$ $\mathrm{c} / \mathrm{mL}$ ) using Mantel-Haenszel weights. Exploratory analyses in each baseline viral load stratum were also performed.

Descriptive statistics were used to evaluate the secondary efficacy endpoints. ITT(E) and Observed analyses were carried out for the proportions of subjects with plasma HIV-1 RNA $<400 \mathrm{c} / \mathrm{mL}$ and $<50 \mathrm{c} / \mathrm{mL}$ at week 48 using $\mathrm{M} / \mathrm{S}=\mathrm{F}$ and $\mathrm{M}=\mathrm{F}$, overall and stratified by baseline viral load stratum. Kaplan-Meier estimates were calculated for the time to first study-defined virologic failure and the time to loss of virologic response (TLOVR).

The safety population included all randomized patients who consumed at least one dose of study drug and were analyzed by the actual treatment received. Adverse events (AEs) were graded by the investigator according to the Division of AIDS toxicity table (1992) and coded by an adverse event dictionary (MedDRA) [9]. Grade 2-4 AEs (moderate to severe in intensity), treatment-related AEs, and serious AEs were collected. No statistical inferences were performed for these summaries. Changes from baseline in fasting insulin levels, HOMA-IR, QUICKI, and lipid profiles (total cholesterol, high-density lipoprotein, low-density lipoprotein, and triglycerides) were tabulated.

Adherence was calculated as the ratio of the total number of doses taken to the total number of doses that should have been taken. The numerator of the ratio was calculated as the number of tablets dispensed minus the number of tablets returned.

Genotypic summaries were based on differences in the plasma virus sequence from the molecular wild-type strain NL4-3. Reverse transcriptase (RT) and protease (PRO) mutations associated with the development of resistance to antiretroviral therapy as listed by the International AIDS Society (IAS) Drug Resistance Mutation Group were used in the analyses [10].

All analyses were performed using SAS ${ }^{\circledast}$ v8 (SAS Institute, Cary, NC) on a system of UNIX computers.

\section{Results \\ Study Population}

Two hundred and seventy-nine (279) subjects were enrolled between May 2004 and March 2005; and the ITT(E) population consisted of 278 subjects. Table 2 summarizes the demographics and baseline characteristics, which were well-matched between the treatment groups. Overall, the study population was predominantly male $(79 \%)$ and racially diverse ( $>50 \%$ non-white race or ethnicity). Most subjects ( $82 \%$ ) had an HIV-1 RNA $<100,000$ $\mathrm{c} / \mathrm{mL}$ at baseline. Seven subjects $(5 \%)$ in the ABC/3TC/ ZDV group and 9 subjects $(6 \%)$ in the ATV+3TC/ZDV group were included in the switch population for suspected $A B C$ hypersensitivity and ATV treatment-limiting toxicities, respectively. No pregnancies or deaths occurred during the study.

Subject disposition through 48 weeks is shown in Figure 1. Data from 3 subjects in the $\mathrm{ABC} / 3 \mathrm{TC} / \mathrm{ZDV}$ group were not retrievable due to Hurricane Katrina damage in 
Table 2: Baseline Demographics and Characteristics

\begin{tabular}{|c|c|c|}
\hline & ABC/3TC/ZDV $(N=139)$ & ATV+3TC/ZDV $(N=\mid 40)$ \\
\hline Median Age, years (range) & $38(19-65)$ & $36(18-68)$ \\
\hline Female Gender, n (\%) & $30(22 \%)$ & $28(20 \%)$ \\
\hline \multicolumn{3}{|l|}{ Race, $n(\%)$} \\
\hline White & $65(47 \%)$ & $58(41 \%)$ \\
\hline Black & $44(32 \%)$ & $49(35 \%)$ \\
\hline American Hispanic & $26(19 \%)$ & $29(21 \%)$ \\
\hline Other & $4(3 \%)$ & $4(3 \%)$ \\
\hline CDC Class C, $\mathrm{n}(\%)$ & $6(4 \%)$ & $5(4 \%)$ \\
\hline Median HIV-I RNA, $\log _{10}$ copies/mL (range) & $4.48(2.3-5.5)$ & $4.64(2.6-5.6)$ \\
\hline HIV-I RNA $\geq 100,000$ copies $/ m L, n(\%)$ & $24(17 \%)$ & $25(18 \%)$ \\
\hline Median $\mathrm{CD}^{+}$cell count, (cells $\left./ \mathrm{mm}^{3}\right)$ (range) & $274(103-889)$ & $262(50-749)$ \\
\hline $\mathrm{CD}^{+}$cell count $\geq 200$ cells $/ \mathrm{mm}^{3}, \mathrm{n}(\%)$ & $105(76 \%)$ & 97 (69\%) \\
\hline Hepatitis B positive, n (\%) & $2(1 \%)$ & $6(4 \%)$ \\
\hline Hepatitis C positive, n (\%) & $9(6 \%)$ & $10(7 \%)$ \\
\hline Hepatitis \& B positive, $n(\%)$ & 0 & $\mathrm{I}(<1 \%)$ \\
\hline
\end{tabular}

Abbreviations: abacavir sulfate (ABC), atazanavir (ATV), lamivudine (3TC), zidovudine (ZDV)

August 2005. In addition, subjects that met the protocoldefined definition of virologic failure were permitted to remain on study if their VL remained less than $1265 \mathrm{c} / \mathrm{mL}$ (1/2 log above $400 \mathrm{c} / \mathrm{mL})$. Thus, some subjects appear twice in the summary of study outcome (Table 3 ), as virologic failures and as study completers. Overall, $74 \%$ of subjects in the $\mathrm{ABC} / 3 \mathrm{TC} / \mathrm{ZDV}$ group and $70 \%$ of subjects in ATV+3TC/ZDV group completed the study.

\section{Efficacy}

The non-inferiority of $\mathrm{ABC} / 3 \mathrm{TC} / \mathrm{ZDV}$ to ATV+3TC/ZDV was established since $62 \%(85 / 138)$ vs. $59 \%(83 / 140)$ of subjects achieved an HIV-1 RNA $<50 \mathrm{c} / \mathrm{mL}$ and were considered virologic responders in the primary efficacy analysis at week 48, [ITT(E), M/S = F, 95\% CI: -5.9, 10.4] (Figure 2). Similarly, in the Observed analysis, 76\% (85/ $112)$ vs. $74 \%$ (83/112) of subjects in the $\mathrm{ABC} / 3 \mathrm{TC} / \mathrm{ZDV}$ group vs. ATV+3TC/ZDV group achieved a $\mathrm{VL}<50 \mathrm{c} / \mathrm{mL}$ at week 48, [ITT(E), S = F 95\% CI: -6.7, 9.4].

In exploratory stratified analyses, similar results were observed in the 230 subjects with baseline $\mathrm{VL}<100,000 \mathrm{c} /$ $\mathrm{mL}(\mathrm{ABC} / 3 \mathrm{TC} / \mathrm{ZDV}$ vs. ATV+3TC/ZDV), 66\% (76/115) vs. 59\% (68/115); 95\% CI: -5.6, 19.5, suggesting that $A B C /$ 3TC/ZDV was virologically non-inferior to ATV+3TC/ZDV in the low viral load stratum (Figure 3 ). In contrast, among the 48 subjects with baseline $\mathrm{VL} \geq 100,000 \mathrm{c} / \mathrm{mL}$ (ABC/3TC/ZDV vs. ATV+3TC/ZDV), 39\% (9/23) vs. $60 \%$ $(15 / 25)$ achieved a $\mathrm{VL}<50 \mathrm{c} / \mathrm{mL}$ at week $48 ; 95 \% \mathrm{CI}:-49.2$, 7.4 , suggesting that $\mathrm{ABC} / 3 \mathrm{TC} / \mathrm{ZDV}$ did not meet the noninferiority criterion compared to ATV+3TC/ZDV in the high viral load stratum. Further, the confidence interval suggests that ATV+3TC/ZDV was non-inferior to $A B C /$ 3TC/ZDV in the high viral load stratum of this study. Comparable results were seen in stratified Observed anal- yses at week $48(\mathrm{ABC} / 3 \mathrm{TC} / \mathrm{ZDV}$ vs. ATV+3TC/ZDV); $<100,000 \mathrm{c} / \mathrm{mL}$ stratum $(81 \%$ vs. $76 \% ; 95 \% \mathrm{CI}:-7.5$, 16.4 ) and $\geq 100,000 \mathrm{c} / \mathrm{mL}$ stratum ( $50 \%$ vs. $65 \%$; $95 \%$ CI: $-46.2,15.8)$. Sensitivity analyses demonstrated no differences in efficacy when subjects with missing data resulting from Hurricane Katrina were excluded.

Secondary analyses of the primary efficacy endpoint in which subjects with toxicity switches were not considered failures, for both the overall population and by viral load strata, resulted in consistent results for both the $\mathrm{M}=\mathrm{F}$ and observed examinations. At week 48,67\% (93/138) vs. $68 \%(95 / 140)$ of subjects in the $\mathrm{ABC} / 3 \mathrm{TC} / \mathrm{ZDV}$ vs. ATV+3TC/ZDV group achieved a VL $<400 \mathrm{c} / \mathrm{mL}$ [ITT(E), $M=F]$ (Figure 2). Similar results were seen in the Observed analysis; $92 \%$ (93/101) vs. 96\% (95/99) of subjects in $\mathrm{ABC} / 3 \mathrm{TC} / \mathrm{ZDV}$ vs. ATV+3TC/ZDV group, respectively. The proportion of subjects $(\mathrm{ABC} / 3 \mathrm{TC} / \mathrm{ZDV}$ vs. ATV+3TC/ZDV) that achieved a $\mathrm{VL}<50 \mathrm{c} / \mathrm{mL}$ when toxicity switches were not considered failures was 64\% (89/ $138)$ vs. $63 \%(88 / 140)$ [ITT(E), $M=F]$ and $80 \%$ in each treatment group [(89/111) vs. (88/110)] in Observed analyses, respectively (Figure 3 ).

Immunologic recovery was observed in both treatment groups at week 48 . The median change from baseline in CD4+ cell count was an increase of 147 cells $/ \mathrm{mm}^{3}$ in both groups resulting in a median CD4+ cell count of 434 cells/ $\mathrm{mm}^{3}$ in the $\mathrm{ABC} / 3 \mathrm{TC} / \mathrm{ZDV}$ group and 419 cells $/ \mathrm{mm}^{3}$ in the ATV+3TC/ZDV group.

Protocol-defined virologic failure occurred in 18 (13\%) vs. $17(12 \%)$ of subjects in the $\mathrm{ABC} / 3 \mathrm{TC} / \mathrm{ZDV}$ vs. ATV+3TC/ZDV group, respectively (Table 4). Three subjects in the $\mathrm{ABC} / 3 \mathrm{TC} / \mathrm{ZDV}$ group and 6 subjects in the 


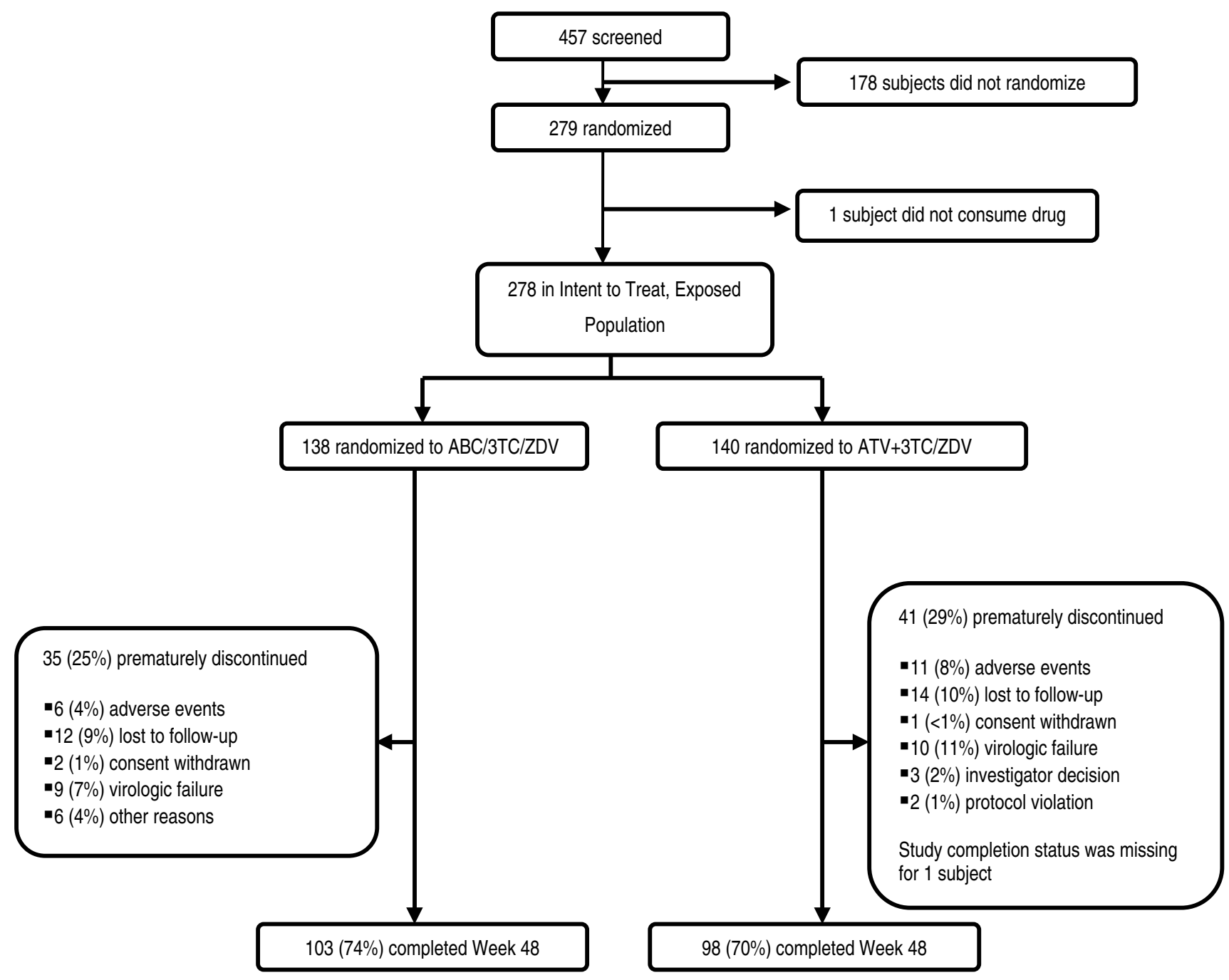

Figure I

Subject Disposition.

ATV+3TC/ZDV group met multiple virologic failure criteria. Overall, subjects were more likely to experience virologic rebound after week 24 in the ATV+3TC/ZDV group while more subjects in the $\mathrm{ABC} / 3 \mathrm{TC} / \mathrm{ZDV}$ group had a VL $>400 \mathrm{c} / \mathrm{mL}$ without confirmation at week 48. Regardless of strata, a similar proportion of subjects experienced protocol-defined virologic failure independent of treatment arm. As noted in Figure 4, no difference in time to loss of virologic response between treatment groups was observed. Additionally, adherence to randomized therapy was high (median $>97.5 \%$ ) in both groups.

\section{Safety}

The safety population consisted of 278 subjects (138 ABC/3TC/ZDV; 140 ATV+3TC/ZDV) who were analyzed based on treatment received. One subject randomized to
$\mathrm{ABC} / 3 \mathrm{TC} / \mathrm{ZDV}$ was dispensed ATV+3TC/ZDV for the duration of the study and was analyzed based on the actual treatment received. The overall incidence of Grade 2-4 adverse events was similar between arms; $72 \%$ in each group. Treatment-related Grade 2-4 adverse events occurred less frequently in the ABC/3TC/ZDV group with notably different toxicities between groups (Table 5). Hyperbilirubinemia was the most frequently reported adverse event occurring in $21 \%$ of subjects in the ATV+3TC/ZDV group followed by nausea in $11 \%$ of subjects in the $\mathrm{ABC} / 3 \mathrm{TC} / \mathrm{ZDV}$ group and $4 \%$ of subjects in the ATV+3TC/ZDV group. Treatment-related serious adverse events were reported by 10 subjects (7 ABC/3TC/ZDV; 3 ATV+3TC/ZDV). Suspected abacavir hypersensitivity reactions (ABC HSR) were considered serious adverse events and were reported in 7 (5\%) subjects receiving ABC/3TC/ 
Table 3: Study Outcomes at Week 48

\begin{tabular}{|c|c|c|}
\hline & ABC/3TC/ZDV $(\mathbf{N}=138)$ & ATV+3TC/ZDV $(\mathrm{N}=140)$ \\
\hline Completed study & $103(74 \%)$ & $98(70 \%)$ \\
\hline Prematurely withdrawn' & $36(26 \%)$ & $4 \mathrm{I}(29 \%)$ \\
\hline Virologic Failures & $18(13 \%)$ & $17(12 \%)$ \\
\hline \multicolumn{3}{|c|}{ Primary Reason for Withdrawal ${ }^{2}, \mathrm{n}(\%)$} \\
\hline Adverse event & $6(4 \%)$ & II (8\%) \\
\hline Lost to follow-up & $12(9 \%)$ & $14(10 \%)$ \\
\hline Protocol defined virologic failure ${ }^{3}$ & $16(12 \%)$ & $16(11 \%)$ \\
\hline Subject decision & $3(2 \%)$ & $\mathrm{I}(<1 \%)$ \\
\hline Protocol violation & 0 & $2(1 \%)$ \\
\hline Investigator decision & 0 & $3(2 \%)$ \\
\hline Other ${ }^{4}$ & $6(4 \%)$ & 0 \\
\hline
\end{tabular}

I. One subject in the ATV+3TC/ZDV group had a missing completion status.

2. As reported by study investigators on Study Conclusion case report form.

3. Subjects with confirmed virologic failure with subsequent HIV-I RNA $<1265$ copies $/ \mathrm{mL}$ were allowed to remain in the study on randomized treatment; therefore the actual number of virologic failures is greater than the number that withdrew from study. In the ABC/3TC/ZDV group, 7 virologic failures completed the study and 2 were lost to follow-up. In the ATV+3TC/ZDV group, 6 virologic failures completed the study and I was withdrawn with a protocol violation.

4. Other included (number of subjects): incarceration (2), site not operational due to Hurricane Katrina (3), moved out of state (I).

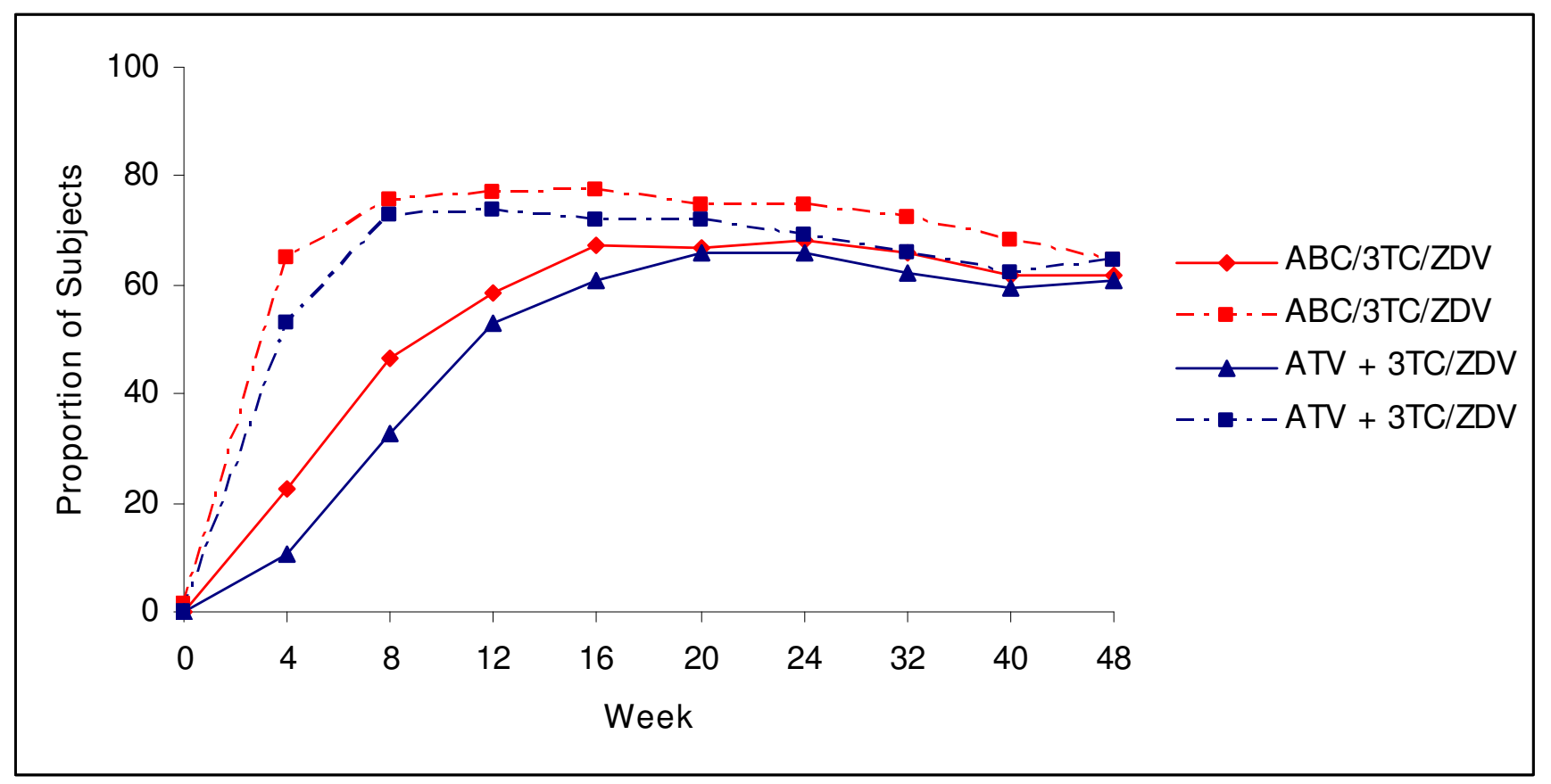

\section{Figure 2}

Proportion of subjects with HIV-I RNA $<50$ and $<400$ copies/mL through Week 48. Proportion of patients with HIV-I RNA < 50 copies/mL (solid line) and < 400 copies/mL (dashed line): ITT(E), M/S = F analysis. 


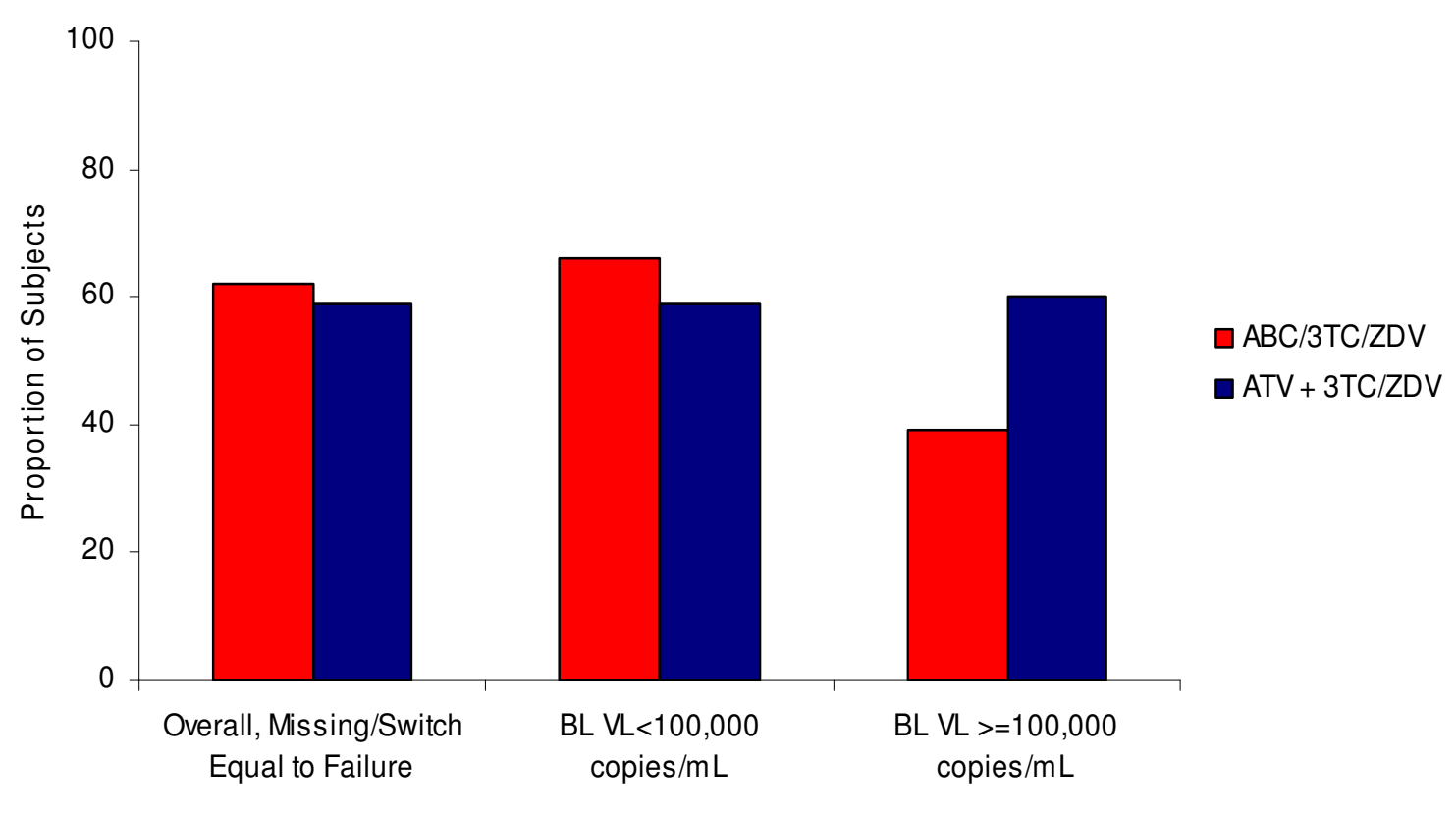
$\mathrm{n}=138$
115
23
ATV $+3 T C / Z D V \quad n=140$
115
25

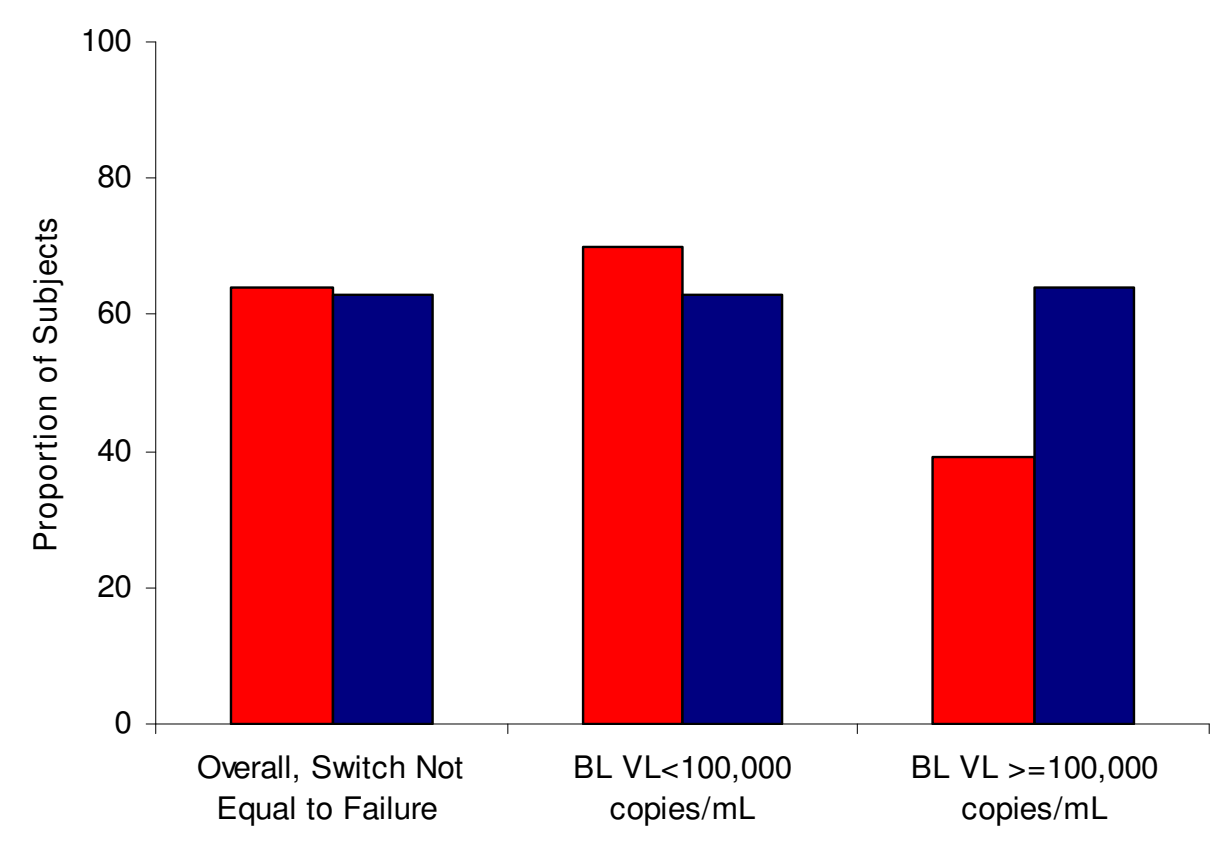
ABC/3TC/ZDV
$\mathrm{n}=138$
115
23
$A T V+3 T C / Z D V \quad n=140$
115
25

Figure 3

Proportion of subjects with HIV-I RNA $<50$ copies/mL by baseline HIV-I RNA at Week 48. Analyses include switch equal to failure (top) and switch not equal to failure (bottom). 


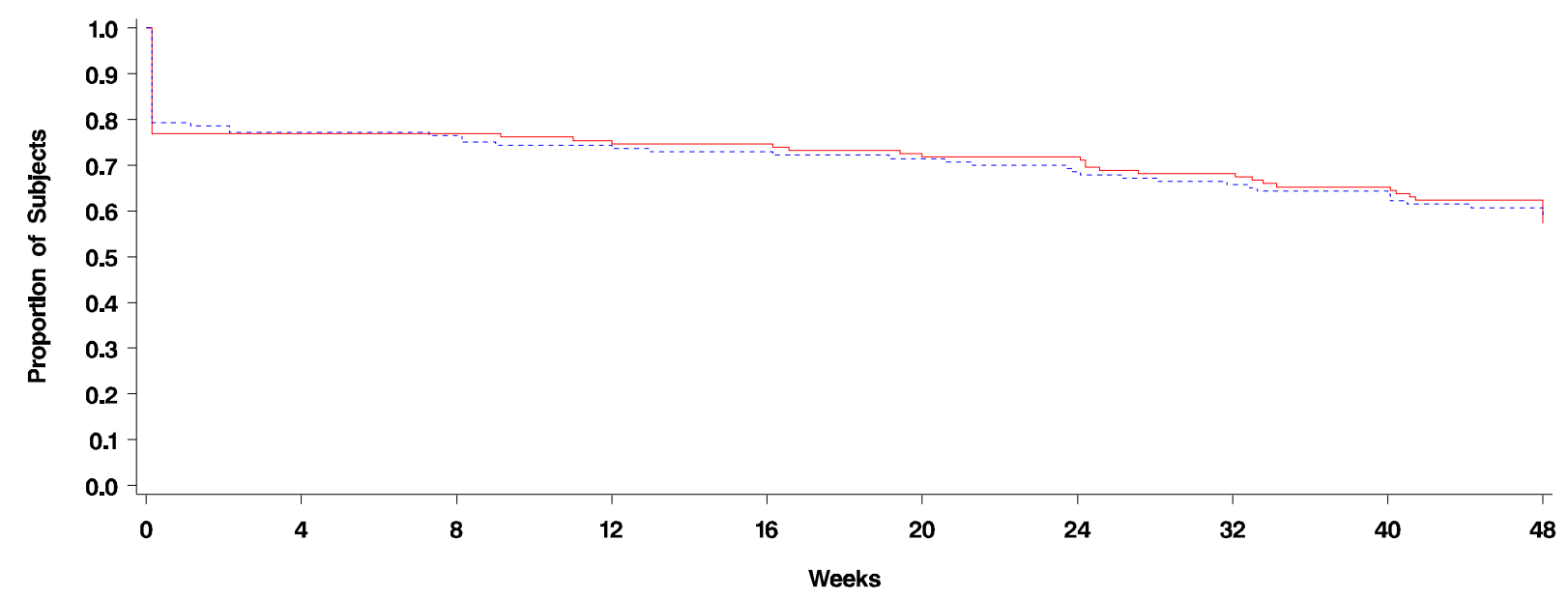

Subjects at Risk $\mathrm{ABC} / 3 \mathrm{TC} / \mathrm{ZDV}$ $A T V+3 T C / Z D V$

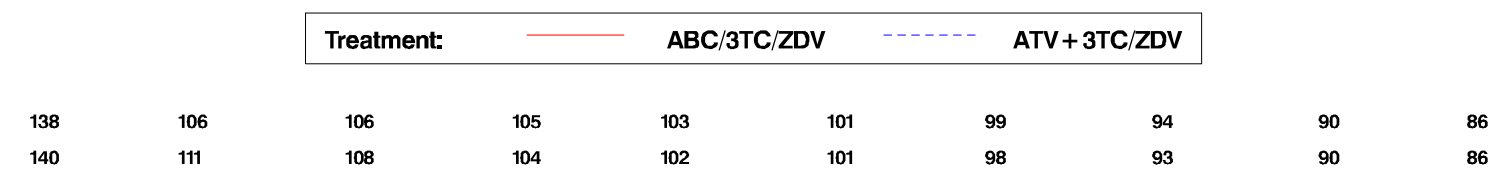

Figure 4

Time to loss of virologic response ( $<50$ copies $/ \mathrm{mL})$.

Table 4: Summary of Protocol-Defined Virologic Failure and Drug Resistance at Week 48

\begin{tabular}{|c|c|c|}
\hline & $\begin{array}{l}\text { ABC/3TC/ZDV } \\
(\mathbf{N}=138)\end{array}$ & $\begin{array}{l}\text { ATV+3TC/ZDV } \\
(\mathbf{N}=140)\end{array}$ \\
\hline Virologic Responders & $120(87 \%)$ & $123(88 \%)$ \\
\hline Protocol-Defined Virologic Failures & $18(13 \%)$ & $17(12 \%)$ \\
\hline I. Less than I $\log _{10}$ reduction in baseline plasma HIV-I RNA by week 12 & 3 & 3 \\
\hline $\begin{array}{l}\text { 2. Reduction of plasma HIV-I RNA }<50 \text { copies } / \mathrm{mL} \text { on two occasions with a subsequent increase } \\
\text { to } \geq 400 \text { copies } / \mathrm{mL} \text { on two consecutive occasions prior to week } 24\end{array}$ & 2 & 2 \\
\hline 3. Failure to achieve plasma HIV-I RNA < 400 copies/mL by Week 24 & 3 & 4 \\
\hline 4. Plasma HIV-I RNA $\geq 400$ copies $/ \mathrm{mL}$ on consecutive occasions after Week 24 & 6 & 11 \\
\hline 5. Plasma HIV-I RNA $\geq 400$ copies $/ \mathrm{mL}$ at Week 48 without confirmation & 7 & 3 \\
\hline Subjects meeting multiple virologic failure criterial & 3 & 5 \\
\hline Post-Baseline Genotype and Phenotype & 17 & 16 \\
\hline Subjects with treatment-emergent mutations & 10 & 11 \\
\hline Any NRTI-associated Mutations ${ }^{2}$ & 8 & 9 \\
\hline \multicolumn{3}{|l|}{ (MI84V, MI84M/V, L74V, L74I/V D67N, L2I0W) } \\
\hline 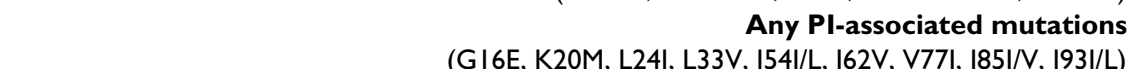 & 7 & 6 \\
\hline $\begin{array}{r}\text { Any NNRTI-associated mutations } \\
(\mathrm{K} \mid 03 \mathrm{~N})\end{array}$ & 0 & 1 \\
\hline
\end{tabular}

Note: Genotype at screening was not performed.

I. In the ABC/3TC/ZDV group, I subject met both criteria 2 and 5 and 2 subjects met both criteria 4 and 5 ; In the ATV+3TC/ZDV group, I subject met criteria 2 and 4,3 subjects met criteria 3 and 4, and I subject met criteria 4 and 5 .

2. Treatment-emergent mutations that were considered non-significant that also developed included: F77L, II3V, L63L/P, L63P, and E35G. 
Table 5: Grade 2-4 Treatment-Related Adverse Events \& Laboratory Abnormalities Occurring in $\geq 2 \%$ of Subjects

\begin{tabular}{lcc}
\hline & ABC/3TC/ZDV (N = I38) & ATV+3TC/ZDV (N = I40) \\
\hline Any Grade 2-4 event (Grade 3-4) & $\mathbf{3 0 \% ( 7 \% )}$ & $\mathbf{4 7 \% ( 2 5 \% )}$ \\
Hyperbilirubinemia & 0 & $21 \%(15 \%)$ \\
Nausea & $11 \%(<1 \%)$ & $4 \%(0)$ \\
Headache & $4 \%(<1 \%)$ & $4 \%(0)$ \\
Neutropenia & $4 \%(4 \%)$ & $5 \%(4 \%)$ \\
Fatigue & $5 \%(<1 \%)$ & $2 \%(0)$ \\
Suspected Abacavir Hypersensitivityl & $5 \%(0)$ & 0 \\
Vomiting & $2 \%(0)$ & $2 \%(0)$ \\
Anemia & $<1 \%(<1 \%)$ & $3 \%(3 \%)$ \\
Ocular Icterus & 0 & $4 \%(2 \%)$ \\
Abdominal pain & $2 \%(0)$ & $<1 \%(0)$ \\
Increased Creatinine Phosphokinase & 0 & $2 \%(1 \%)$ \\
Rash & 0 & $2 \%(0)$ \\
\hline
\end{tabular}

I Includes I report of a Grade-I suspected abacavir hypersensitivity reaction

ZDV of which 6 were classified as Grade-2 and 1 as a Grade-1 event; none of the subjects experiencing a suspected ABC HSR discontinued study. In the ATV+3TC/ ZDV group, 3 (2\%) subjects reported anemia (2-Grade 3, 1 -Grade 4) each requiring blood transfusions, two of whom discontinued from study.
Treatment-emergent Grade 3-4 laboratory abnormalities were infrequent and generally comparable between groups (Table 5). Grade 3-4 hyperbilirubinemia occurred in $15 \%$ of subjects treated with ATV+3TC/ZDV. Two subjects discontinued study for atazanavir-related treatment toxicities, 1 for jaundice and 1 for hyperbilirubinemia. Additionally, 4 subjects receiving atazanavir elected to

Table 6: Median Fasting Lipid and Metabolic Parameters at Baseline and Week 48

\begin{tabular}{|c|c|c|c|c|c|c|}
\hline \multirow[b]{2}{*}{ Median (range) } & \multicolumn{3}{|c|}{$\begin{array}{c}A B C / 3 T C / Z D V \\
N=138\end{array}$} & \multicolumn{3}{|c|}{$\begin{array}{c}A T V+3 T C / Z D V \\
N=140\end{array}$} \\
\hline & $\begin{array}{c}\text { Number Tested } \\
\text { (Baseline, Week 48) }\end{array}$ & Baseline & Week 48 & $\begin{array}{c}\text { Number Tested } \\
\text { (Baseline, Week 48) }\end{array}$ & Baseline & Week 48 \\
\hline TC (mg/dL) & 131,93 & $\begin{array}{c}162 \\
(95-255)\end{array}$ & $\begin{array}{c}176 \\
(102-305)\end{array}$ & 137,93 & $\begin{array}{c}160 \\
(7 \mid-276)\end{array}$ & $\begin{array}{c}|7| \\
(68-288)\end{array}$ \\
\hline LDL (mg/dL) & 127,89 & $\begin{array}{c}98 \\
(6-165)\end{array}$ & $\begin{array}{c}99 \\
(20-198)\end{array}$ & 133,92 & $\begin{array}{c}97 \\
(31-200)\end{array}$ & $\begin{array}{c}101.5 \\
(10-200)\end{array}$ \\
\hline $\mathrm{HDL}(\mathrm{mg} / \mathrm{dL})$ & 131,93 & $\begin{array}{c}36.5 \\
(6-74)\end{array}$ & $\begin{array}{c}44 \\
(2 I-75)\end{array}$ & 135,93 & $\begin{array}{c}33 \\
(7-77)\end{array}$ & $\begin{array}{c}44 \\
(18-90)\end{array}$ \\
\hline TG (mg/dL) & 131,93 & $\begin{array}{c}113 \\
(38-62 I)\end{array}$ & $\begin{array}{c}126 \\
(42-1231)\end{array}$ & 137,93 & II (4I-559) & $\begin{array}{c}110 \\
(44-407)\end{array}$ \\
\hline Glucose (mg/dL) & 119,91 & $\begin{array}{c}95 \\
(60-199)\end{array}$ & $\begin{array}{c}98 \\
(5-268)\end{array}$ & 126,93 & $\begin{array}{c}89.5 \\
(58-131)\end{array}$ & $\begin{array}{c}95 \\
(72-166)\end{array}$ \\
\hline Insulin $(\mu \mathrm{IU} / \mathrm{mL})$ & 117,79 & $\begin{array}{c}10 \\
(2-128)\end{array}$ & $\begin{array}{c}13 \\
(2-56)\end{array}$ & 119,83 & $\begin{array}{c}10 \\
(2-61)\end{array}$ & $\begin{array}{c}12 \\
(4-132)\end{array}$ \\
\hline HOMA-IR+ & 110,83 & $\begin{array}{c}2.2 \\
(0.4-37.5)\end{array}$ & $\begin{array}{c}2.9 \\
(0.4-17.3)\end{array}$ & 112,87 & $\begin{array}{c}2.4 \\
(0.4-19.5)\end{array}$ & $\begin{array}{c}3 \\
(0.9-51.6)\end{array}$ \\
\hline QUICKI++ & 110,83 & $\begin{array}{c}0.59 \\
(0.34-1.05)\end{array}$ & $\begin{array}{c}0.54 \\
(0.38-1.00)\end{array}$ & 112,87 & $\begin{array}{c}0.58 \\
(0.37-1.00)\end{array}$ & $\begin{array}{c}0.54 \\
(0.32-0.77)\end{array}$ \\
\hline
\end{tabular}

+ HOMA-IR $=[$ Fasting Insulin $(\mu \mathrm{IU} / \mathrm{mL}) \times$ Fasting Glucose $(\mathrm{mg} / \mathrm{dL})) /(22.5 \times 18)]$;

${ }^{++}$QUICKI $=1 /[$ log Fasting Insulin $(\mu \mathrm{lU} / \mathrm{mL})]+[$ log Fasting Glucose $(\mathrm{mg} / \mathrm{dL})]$ 
switch to fosamprenavir for asymptomatic, grade 3 hyperbilirubinemia without clinical evidence of jaundice or scleral icterus. Grade 3-4 neutropenia was reported in 10 subjects; $4 \% \mathrm{ABC} / 3 \mathrm{TC} / \mathrm{ZDV} ; 4 \% \mathrm{ATV}+3 \mathrm{TC} / \mathrm{ZDV}$. Changes in fasting lipids and glucose were comparable in both treatment groups (Table 6 ). At week 48 , median triglycerides were $126 \mathrm{mg} / \mathrm{dL}$ in the $\mathrm{ABC} / 3 \mathrm{TC} / \mathrm{ZDV}$ group compared with $110 \mathrm{mg} / \mathrm{dL}$ in the ATV+3TC/ZDV group. However, all median fasting lipid parameters were below NCEP ATP III thresholds for both groups at week 48 $[11,12]$. Changes in glucose, insulin sensitivity and insulin resistance were minimal and comparable between groups. The use of concurrent lipid lowering medications was minimal; 5 subjects received statins $(2 \mathrm{ABC} / 3 \mathrm{TC} /$ ZDV; 3 ATV+3TC/ZDV) and 1 subject in the ABC/3TC/ ZDV group received a fibrate.

There were no myocardial infarctions reported in the ABC/3TC/ZDV arm. Two cases of non-cardiac chest pain (both confirmed by a negative diagnostic evaluation) were reported in the $\mathrm{ABC} / 3 \mathrm{TC} / \mathrm{ZDV}$ arm. In the ATV + 3TC/ZDV arm, 1 case of confirmed myocardial infarction/ coronary occlusion was reported. All 3 cases were reported as not-related to study drug.

\section{Viral Resistance}

Thirty-five subjects (13\%) $\quad\left[\begin{array}{ll}18 & \mathrm{ABC} / 3 \mathrm{TC} / \mathrm{ZDV} ; \quad 17\end{array}\right.$ ATV+3TC/ZDV] met one or more protocol-defined virologic failure criteria. Paired genotypes and phenotypes were available for $17 / 18$ subjects in the $A B C / 3 T C / Z D V$ group and 16/17 subjects in the ATV+3TC/ZDV group at baseline and at the time of virologic failure (Table 4).

Among the 35 subjects with virologic failure, $11.4 \%$ had primary NRTI or NNRTI mutations and 5.7\% had primary $\mathrm{PI}$-associated resistance mutations at baseline. Three subjects $(2 \mathrm{ABC} / 3 \mathrm{TC} / \mathrm{ZDV}$ and $1 \mathrm{ATV}+3 \mathrm{TC} / \mathrm{ZDV})$ with virologic failure had primary $\mathrm{ABC}-$ and/or 3TC-related mutations at baseline. Primary PI mutations were present at baseline in 2 subjects experiencing virologic failure [ 1 D30N (ABC/3TC/ZDV); 1 L90M (ATV+3TC/ZDV)] and the NNRTI-associated K103N mutation was present in 1 subject receiving ATV+3TC/ZDV. Treatment-emergent ABC- and/or 3TC-associated mutations occurred in 10 subjects failing $\mathrm{ABC} / 3 \mathrm{TC} / \mathrm{ZDV}$, the majority of which developed the M184V mutation and to a lesser extent, minor PI mutations suggesting these subjects had virus harboring PI drug-resistance at baseline. In the ATV+3TC/ ZDV group, 11 subjects had treatment-emergent mutations; 11 subjects developed the $\mathrm{M} 184 \mathrm{~V}$ nucleoside mutation, 1 subject developed $\mathrm{K} 103 \mathrm{~N}$, and 6 subjects developed minor PI mutations. No major ATV-related mutations developed over 48 weeks.
Treatment-emergent drug resistance occurred in subjects experiencing virologic failure in both treatment arms. Among the 35 subjects (13\%) experiencing virologic failure, the M184V mutation developed most commonly in $46 \%(16 / 35)$ of subjects. Among subjects with paired phenotypic data, $45 \%(15 / 33)$ had no drug-associated reduced susceptibility present while 55\% (18/33) had reduced phenotypic susceptibility present on treatment. No subject had primary PI resistance at the time of virologic failure as defined by IAS-USA guidelines [10]. These results suggest that subjects failing on either treatment regimen may have therapy options available given that crossresistance to other members in the nucleoside and protease inhibitor classes was not seen.

\section{Discussion}

ACTION was one of the first studies to evaluate the safety and efficacy of $\mathrm{ABC} / 3 \mathrm{TC} / \mathrm{ZDV}$ compared to atazanavir, the latter which was approved approximately 1 year prior to initiation of present study. This study demonstrated the virologic non-inferiority of $\mathrm{ABC} / 3 \mathrm{TC} / \mathrm{ZDV}$ compared to ATV+3TC/ZDV in this study population over 48 weeks. Virologic and immunologic responses were similar between the treatment arms $(\mathrm{ABC} / 3 \mathrm{TC} / \mathrm{ZDV}$ vs. ATV $+3 T C / Z D V)$ given $62 \%$ vs. $59 \%$ of subjects achieved an HIV-1 RNA $<50 \mathrm{c} / \mathrm{mL}$ and the median CD4+ cell count increase was 147 cells $/ \mathrm{mm}^{3}$ in both groups at week 48 . Similar responses were also evident in subjects with a lower baseline viral load, as $66 \%$ and $59 \%$ of subjects in the $\mathrm{ABC} / 3 \mathrm{TC} / \mathrm{ZDV}$ group and $\mathrm{ATV}+3 \mathrm{TC} / \mathrm{ZDV}$ group achieved the primary endpoint. However, virologic response was suboptimal in the ABC/3TC/ZDV (39\%) group of subjects with a higher baseline viral load $(\geq$ $100,000 \mathrm{c} / \mathrm{mL}$ ) compared to those in the ATV+3TC/ZDV group $(60 \%)$. The small number of subjects in the higher viral load strata did not account for the large difference between treatment arms since the study was stratified $a$ priori. However, atazanavir in combination with lamivudine/zidovudine performed well regardless of baseline viral load.

The rate of virologic failure was somewhat higher than expected in this study in both treatment arms, likely due to the use of multiple criteria for virologic failure, $(13 \%$ $\mathrm{ABC} / 3 \mathrm{TC} / \mathrm{ZDV} ; 12 \% \mathrm{ATV}+3 \mathrm{TC} / \mathrm{ZDV})$. A conservative definition of virologic failure was adopted partly in response to the results of the ACTG 5095 study and subsequent change in the Department of Health and Human Services guidelines for antiretroviral therapy reserving triple nucleoside regimens as alternative first line options. Differential treatment responses with $\mathrm{ABC} / 3 \mathrm{TC} / \mathrm{ZDV}$ in patients with higher baseline viral loads have been observed rarely; reduced responses were first observed in those with higher baseline VL $(>100,000 \mathrm{c} / \mathrm{mL})$ when compared to a PIbased regimen in Study CNA3005, and more recently in 
the ACTG 5095 study which demonstrated an inferior virologic response of $\mathrm{ABC} / 3 \mathrm{TC} / \mathrm{ZDV}$ compared to pooled EFV-containing arms with dual and triple nucleoside backbones regardless of pre-treatment VL $(<$ or $\geq 100,000$ c/mL) $[2,5]$.

Since no one particular virologic failure criteria was met more often than another and reported medication adherence was high, this suggests that subjects receiving $A B C /$ 3TC/ZDV are not more likely to experience early virologic non-response than virologic response followed by viral rebound. For select subjects with baseline $\mathrm{VL}<100,000 \mathrm{c} /$ $\mathrm{mL}$, this study demonstrated that subjects receiving $\mathrm{ABC} /$ $3 T C / Z D V$ have an equal opportunity for achieving virologic success as those receiving an ATV-containing regimen without low-dose ritonavir boosting.

The unexpected appearance of treatment-emergent PI mutations among subjects receiving $\mathrm{ABC} / 3 \mathrm{TC} / \mathrm{ZDV}$ may have been attributed to the emergence of virus harboring low levels of PI mutations undetectable at baseline from either prior PI experience or acquisition of drug-resistance virus. Similarly, the development of the K103N mutation in a subject receiving ATV+3TC/ZDV suggests virus with prior exposure to NNRTIs. Phenotypic resistance toward either treatment regimen was observed infrequently suggesting that subjects failing either treatment may have within-class therapy options available given that crossresistance to other members in the nucleoside and protease inhibitor classes was not seen.

Both regimens were generally well-tolerated and a comparable number of subjects, $4 \%$ vs. $8 \%$, discontinued study resulting from adverse effects in the $\mathrm{ABC} / 3 \mathrm{TC} / \mathrm{ZDV}$ vs. $\mathrm{ATV}+3 \mathrm{TC} / \mathrm{ZDV}$ group, respectively. Investigators were permitted to switch patients off atazanavir for the management of asymptomatic hyperbilirubinemia as per practice in previous initial studies conducted by BMS [13].

Changes in fasting lipids and metabolic parameters were minimal in this study. Median triglycerides were somewhat higher in the $\mathrm{ABC} / 3 \mathrm{TC} / \mathrm{ZDV}$ group compared to the ATV+3TC/ZDV group (126 vs. $110 \mathrm{mg} / \mathrm{dL})$; increases in total cholesterol (176 vs. $171 \mathrm{mg} / \mathrm{dL}$ ) were driven by favorable increases in HDL cholesterol, however, all other lipid parameters were essentially unchanged from baseline. The minimal changes in fasting lipids are of limited clinical significance given all parameters were below target NCEP ATP III recommendations and were similar to other published reports $[8,14-16]$. No differences in serum fasting glucose, insulin, HOMA-IR or QUICKI were observed between treatment arms over 48 weeks.

A fixed dose combination of ABC/3TC/ZDV provides an effective, generally well-tolerated, and simplified triple nucleoside regimen for select antiretroviral naïve subjects with baseline viral loads $<100,000 \mathrm{c} / \mathrm{mL}$. This dosing regimen may be advantageous as an alternative regimen for subjects with pre-existing co-morbidities, history of polypharmacy with drug-drug interaction potential for whom an NNRTI or PI-containing regimen would be challenging. For select patients who cannot tolerate the recommended first line therapy options, both $\mathrm{ABC} / 3 \mathrm{TC} / \mathrm{ZDV}$ and ATV+3TC/ZDV have demonstrated both efficacy and safety in this study conferring an important role for these therapies in both newly HIV-1 infected adults as well as in the aging HIV-1 infected population of the United States.

\section{Conclusion}

A fixed dose combination of $\mathrm{ABC} / 3 \mathrm{TC} / \mathrm{ZDV}$ provides an effective, generally well-tolerated, and simplified triple nucleoside regimen for select antiretroviral naïve subjects with baseline viral loads $<100,000 \mathrm{c} / \mathrm{mL}$. This dosing regimen may be advantageous as an alternative regimen for subjects with pre-existing co-morbidities, history of polypharmacy with drug-drug interaction potential for whom an NNRTI or PI-containing regimen would be challenging. For select patients who cannot tolerate the recommended first line therapy options, both $A B C / 3 T C / Z D V$ and ATV+3TC/ZDV have demonstrated both efficacy and safety in this study conferring an important role for these therapies in both newly HIV-1 infected adults as well as in the aging HIV-1 infected population of the United States.

\section{Competing interests}

PK has participated in speakers bureaus and received research grants from GlaxoSmithKline and Merck. PS and ALM have no relevant competing interests. ED has research grants from Roche Laboratories, Inc. and Gilead Sciences, Inc. and is a Consultant to and/or Advisory Board Member of Bristol-Myers Squibb Company, Gilead Sciences, Inc. (Regional Consultant), GlaxoSmithKline, Roche Laboratories, Inc., and Vertex Pharmaceuticals. PP, $\mathrm{AF}$, and MS are employed by GlaxoSmithKline. DMC was former employee of GlaxoSmithKline.

\section{Authors' contributions}

PNK and PP participated in the analysis and interpretation of the data and the development of the manuscript. $\mathrm{AF}, \mathrm{DM}$, and MS participated in the conception and design of the study, analysis, and interpretation of the data, and development of the manuscript. PS, AL, ED participated in the analysis of the data and development of the manuscript. All authors read and approved the final manuscript.

\section{Acknowledgements}

The authors would like to thank the study participants, clinical investigators, study coordinators, and GlaxoSmithKline staff who made this study successful. Participating investigators were: C Aneziokoro, N Bellos, J Brand, G Coodley, P Cook, E Dejesus, R Dretler, F Felizarta, T File, F Gar- 
cia, E Godofsky, S Green, P Greiger-Zanlungo, J Hernandez, M Hill, M Hoffman-Terry, J Horvath, A Huang, R Jones, P Kumar, P Lackey, A LaMarca, H Lampiris, F Lutz, A Mills, JJ Morales-Reyes, R Nahass, D Parks, R Peskind, D Pitrak, R Poblete, J Ramos-Jimenez, A Rodriguez, J Rodriguez, P Salvato, J Schrank, R Schwartz, R Scott, C Small, D Sweet, E Tedaldi, J Torres, M Tribble, W Weinberg, $R$ Wilcox, and D Wright.

\section{References}

I. Panel on Clinical Practices for the Treatment of HIV Infection: Guidelines for the use of antiretroviral agents in HIV-Iinfected adults and adolescents. Department of Health and Human Services and Henry J. Kaiser Foundation. [http://aid sinfo.nih.gov/guidelines].

2. Staszewski S, Keiser P, Montaner J, Raffi F, Gathe J, Brotas V, Hicks C, Hammer SM, Cooper D, Johnson M, Tortell S, Cutrell A, Thorborn D, Isaacs R, Hetherington S, Steel H, Spreen W: CNAAB3005 International Study Team. Abacavir-lamivudine-zidovudine vs indinavir-lamivudine-zidovudine in antiretroviral-naive HIV-infected adults: A randomized equivalence trial. JAMA 200I, 285: II I55-63.

3. Vibhagool A, Capn P, Schechter M, Smaill F, Soto-Ramirez L, Carosi G, Montroni M, Pharo CE, Jordan JC, Thomas NE, Pearce G: Triple nucleoside treatment with abacavir plus the lamivudinel zidovudine combination tablet (COM) compared to indinavir/COM in antiretroviral therapy-naive adults: results of a 48-week open-label, equivalence trial (CNA30I4). Curr Med Res Opin 2004, 20: I 103-14.

4. Kumar PN, Rodriguez-French A, Thompson MA, Tashima KT, Averitt D, Wannamaker PG, Williams VC, Shaefer MS, Pakes GE, Pappa KA, ESS40002 Study Team: A prospective, 96-week study of the impact of Trizivir, Combivir/nelfinavir, and lamivudine/stavudine/nelfinavir on lipids, metabolic parameters and efficacy in antiretroviral-naive patients: effect of sex and ethnicity. HIV Med 2006, 7:85-98.

5. Gulick RM, Ribaudo HJ, Shikuma CM, Lustgarten S, Squires KE, Meyer WA 3rd, Acosta EP, Schackman BR, Pilcher CD, Murphy RL, Maher WE, Witt MD, Reichman RC, Snyder S, Klingman KL, Kuritzkes DR, AIDS Clinical Trials Group Study A5095 Team: Triple-nucleoside regimens versus efavirenz-containing regimens for the initial treatment of HIV-I infection. N Engl I Med 2004, 350: | 850-6I.

6. Panel on Antiretroviral Guidelines for Adults and Adolescents: Guidelines for the use of antiretroviral agents in HIV-Iinfected adults and adolescents. Department of Health and Human Services 2008:1-139 [http://www.aidsinfo.nih.gov/Content Files/AdultandAdolescentGL.pdf].

7. Malan N, Krantz E, David N, et al.: Efficacy and safety of atazanavir-based therapy in antiretroviral naïve HIV-I infected subjects, both with and without ritonavir: 48-week results from Al424-089 [Abstract 79]. 13th Conference on Retroviruses and Opportunistic Infections; Denver, CO, USA 2006.

8. Reyataz ${ }^{\circledR}$ (atazanavir sulfate) [Product information]. Princeton, NJ: Bristol-Myers Squibb Company; 2007.

9. Division of AIDS, NIAID: Division of AIDS table forgrading severity of adult adverse experiences. Rockville: Nationallnstitute of Allergy and Infectious Diseases; 1992.

10. Hirsch MS, Brun-Vezinet F, Clotet B, Conway B, Kuritzkes DR, D'Aquila RT, Demeter LM, Hammer SM, Johnson VA, Loveday C, Mellors JW, Jacobsen DM, Richman DD: Antiretroviral drug resistance testing in adults infected with human immunodeficiency virus type I: 2003 recommendations of an International AIDS Society-USA Panel. Clin Infect Dis 2003, 37: I I3-28.

II. Grundy SM, Cleeman JI, Merz CN, Brewer HB Jr, Clark LT, Hunninghake DB, Pasternak RC, Smith SC Jr, Stone NJ, Coordinating Committee of the National Cholesterol Education Program. National Heart, Lung, and Blood Institute; American College of Cardiology Foundation; American Heart Association: Implications of recent clinical trials for the National Cholesterol Education Program Adult Treatment Panel III guidelines. Circulation 2004, i 1 0:227-39.

12. Expert Panel on Detection, Evaluation, and Treatment of High Blood Cholesterol in Adults: Executive Summary of the Third Report of the National Cholesterol Education Program (NCEP) Expert Panel on Detection, Evaluation, and Treatment of
High Blood Cholesterol in Adults (Adult Treatment Panel III). JAMA 200I, 285:2486-2497.

13. Sanne I, Piliero P, Squires K, Thiry A, Schnittman S, Al424-007 Clinical Trial Group: Results of a phase 2 clinical trial at 48 weeks (Al424-007): a dose-ranging, safety, and efficacy comparative trial of atazanavir at three doses in combination with didanosine and stavudine in antiretroviral-naïve subjects. J Acquir Immune Defic Syndr 2003, 32: I 8-29.

14. Dube MP, Stein JH, Aberg JA, Fichtenbaum CJ, Gerber JG, Tashima KT, Henry WK, Currier JS, Sprecher D, Glesby MJ, Adult AIDS Clinical Trials Group Cardiovascular Subcommittee; HIV Medical Association of the Infectious Disease Society of America. Adult AIDS Clinical Trials Group Cardiovascular Subcommittee; HIV Medical Association of the Infectious Disease Society of America: Guidelines for the evaluation and management of dyslipidemia in human immunodeficiency virus (HIV)-infected adults receiving antiretroviral therapy: recommendations of the HIV Medical Association of the Infectious Disease Society of America and the Adult AIDS Clinical Trials Group. Clin Infect Dis 2003, 37:613-27.

15. Sutherland-Phillips DH, Hernandez JE, Wannamaker PG, Dix LP, Shaefer MS: Differential effects of nucleoside reverse transcriptase inhibitors (NRTI) with and without a protease inhibitor (PI) or non-nucleoside reverse transcriptase inhibitor (NNRTI) on lipid parameters [Abstract 69]. 8th International Workshop on Adverse Drug Reactions and Lipodystrophy in HIV, San Francisco, CA, USA 2006.

16. Shikuma CM, Yang Y, Glesby MJ, AIDS Clinical Trials Group Protocol A5095 Study Team, et al:: Metabolic effects of protease inhibitor-sparing antiretroviral regimens given as initial treatment of HIV-I infection (AIDS Clinical Trials Group Study A5095). J Acquir Immune Defic Syndr 2007, 44:540-50.
Publish with Bio Med Central and every scientist can read your work free of charge

"BioMed Central will be the most significant development for disseminating the results of biomedical research in our lifetime. "

Sir Paul Nurse, Cancer Research UK

Your research papers will be:

- available free of charge to the entire biomedical community

- peer reviewed and published immediately upon acceptance

- cited in PubMed and archived on PubMed Central

- yours - you keep the copyright 